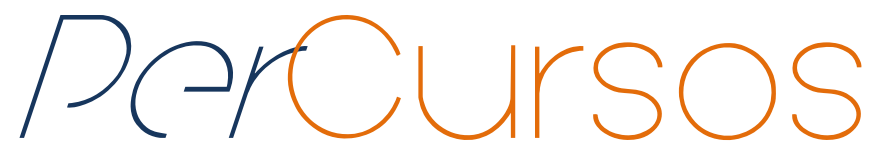

\title{
Entrevista com o Professor Doutor Carlos Xavier Azevedo Netto
}

\author{
Realizada por Eva Cristina Leite da Silva e Marcia Silveira Kroeff em \\ $11 / 09 / 2014$.
}

Carlos Xavier é professor e pesquisador da Universidade Federal da Paraíba - Brasil. Possui graduação em Arqueologia pela Universidade Estácio de Sá - Brasil (1986), mestrado em Artes Visuais pela Universidade Federal do Rio de Janeiro - Brasil (1994) e doutorado em Ciência da Informação pela mesma instituição (2001). É coordenador do Grupo de Trabalho 10 da ANCIB - Associação Nacional de Pesquisa e Pós-Graduação em Ciência da Informação.

\section{Para citar este artigo:}

AZEVEDO NETTO, Carlos Xavier. Entrevista com o Professor Doutor Carlos Xavier Azevedo Netto [Entrevista realizada em 11 de setembro de 2014]. Revista PerCursos, Florianópolis, v. 15, n.29, p. 207 - 210. jul./dez. 2014. Entrevistadoras: Eva Cristina Leite da Silva; Marcia Silveira Kroeff.

DOI: $\mathbf{1 0 . 5 9 6 5 / 1 9 8 4 7 2 4 6 1 5 2 9 2 0 1 4 2 0 7}$

http: //dx.doi.org/10.5965/1984724615292014207 
O Dossiê “Informação, Memória e Sociedade" da Revista PerCursos, organizado pelo Departamento de Biblioteconomia e Gestão da Informação - DBI/FAED/UDESC, com a colaboração do Departamento de Ciência da Informação da Universidade Federal de Santa Catarina - CIN/UFSC, realizou uma entrevista com o Prof. Dr. Carlos Xavier de Azevedo Netto, coordenador do Grupo de Trabalho 10 da ANCIB - Associação Nacional de Pesquisa e Pós-Graduação em Ciência da Informação. O GT 10 - Informação e memória tem como objetivos expressos em sua ementa, realizar "Estudos sobre a relação entre os campos de conhecimento da Ciência da Informação e da Memória Social. Pesquisas transdisciplinares que envolvem conceitos, teorias e práticas do binômio 'informação e memória'. Memória coletiva, coleções e colecionismo, discurso e memória. Representações sociais e conhecimento. Articulação entre arte, cultura, tecnologia, informação e memória, através de seus referenciais, na contemporaneidade. Preservação e virtualização da memória social." Devido à articulação explícita com a temática do presente Dossiê, buscou-se apresentar o GT a partir da experiência de seu coordenador, prof. Dr. Carlos Xavier de Azevedo Netto, que gentilmente se dispôs a apresentar uma breve história do grupo, com apontamentos de sua caminhada, discorrendo também sobre sua caminhada e projetos futuros de atuação. O prof. Carlos Xavier é Bolsista de Produtividade de Pesquisa do CNPq, nível 2, graduado em Arqueologia e com doutorado em Ciência da Informação. É professor Associado da Universidade Federal da Paraíba, no Departamento de Ciência da Informação, atuando como coordenador do Núcleo de Documentação e Informação Histórica Regional - NDIHR, como docente permanente dos Programas de Pós-Graduação em Ciência da Informação - PPGCl e de Antropologia PPGA, ambos da UFPB, bem como, na qualidade de colaborador, do Programa de PósGraduação em Ciência da Informação - PPGCl da UFPE ${ }^{1}$. Esperamos que as informações abaixo apresentadas possam ser úteis a pesquisadores e demais interessados em estudos sobre Informação e Memória.

\footnotetext{
${ }^{1}$ Informações do Currículo Lattes
} 
Revista PerCursos: Inicialmente, poderia nos contar um pouco sobre sua formação acadêmica e atuação como pesquisador nessa linha, relatando também como se deu seu ingresso no GT 10?

Carlos Xavier Azevedo Netto: Minha formação na graduação foi em arqueologia e, desde então, venho trabalhado com a questão dos registros rupestres na pré-história, com minha dissertação de mestrado abordando as gravações existentes no antigo Estado de Goiás, onde pude observar um sério problema informacional na área, que eram os conceitos utilizados para representar os fenômenos observados, com isso ingressei no doutorado em Cl. Não houve ingresso no GT 10, mas sua criação.

Revista PerCursos: Sobre o processo de criação do GT 10 - Informação e Memória - da ANCIB: Poderia abordar, em um breve relato, sua criação, fundadores, principais objetivos e em que contexto o mesmo foi proposto?

Carlos Xavier Azevedo Netto: Na realidade, eu e as professoras Vera Dodebei, Evelyn Orrico, Bernardina Oliveira, Prof ${ }^{\circ}$ Marcos Galindo e outros, no ENANCIB de São Paulo, iniciamos a articulação do que viria a ser o GT 10 - INFORMAÇÃO E MEMÓRIA, que foi deferido para assembleia da ANCIB, no ano seguinte, em João Pessoa.

Revista PerCursos: Desde 2010 até o presente momento, quais foram os avanços mais significativos alcançados pelo Grupo?

Carlos Xavier Azevedo Netto: A primeira contribuição deste GT para a área foi e evidenciação das questões de memória dentro dos estudos da $\mathrm{Cl}$, que antes ficava submerso dentro do GT $02^{2}$. Além disso, vincula o fenômeno informacional, através da perspectiva da memória, como algo que só tem existência dentro de redes e dinâmicas sociais.

Revista PerCursos: Em seu ponto de vista, quais são as principais contribuições do GT para a área de Ciência da Informação no Brasil?

Carlos Xavier Azevedo Netto: A partir dessa explicitação da produção sobre a relação entre informação e memória pode-se apresentar a profusão dos estudos de memória na área e os questionamentos de que memória é essa tratada na $\mathrm{Cl}$.

Revista PerCursos: A partir dos trabalhos que vêm sendo desenvolvidos no GT10, quais seriam as futuras projeções para sua atuação ou expansão?

Carlos Xavier Azevedo Netto: Espera-se que o GT 10 continue com sua missão de expor o desenvolvimento das pesquisas que tratem da relação entre informação e memória, sob seus mais variados caminhos e orientações. Além disso, como contribuição teórica $e$ epistemológica para área, espera-se que se possa chegar a propostas de conceituação de memória que atendam aos contornos da Ciência da Informação.

\footnotetext{
${ }^{2}$ Organização e Representação do Conhecimento
} 
Revista PerCursos: De que forma pesquisadores que ainda não fazem parte do Grupo de Trabalho Informação e Memória, podem vir a atuar no mesmo, como membros integrantes?

Carlos Xavier Azevedo Netto: Existe uma sessão dentro do site da ANCIB exclusiva para a troca de informações entre os sócios da ANCIB interessados na temática, em que são postadas várias notícias sobre o que ocorre de relevante.

Revista PerCursos: Quais os critérios e procedimentos para publicar nas áreas de interesse do GT10 da ANCIB?

Carlos Xavier Azevedo Netto: Não existe um segmento exclusivo de publicações para a temática do GT, estando presente em várias revistas. Para participar das apresentações anuais do GT 10, por ocasião do ENANCIB, basta o interessado se filiar à ANCIB e inscrever um trabalho que tenha fundamentação na discussão do GT e que seja aprovado pelo sistema de avaliação cega pelos avaliadores do GT.

Recebido em: 29/09/2014 Aprovado em: 16/10/2014 